\title{
ANATOMIA DO PÉ E SUAS MALFORMAÇÕES CONGÊNITAS
}

\section{ARTIGO DE REVISÃO}

CORREIA, Carolina de Albuquerque ${ }^{1}$

CARDINOT, Themis Moura ${ }^{2}$

CORREIA, Carolina de Albuquerque. CARDINOT, Themis Moura. Anatomia do pé e suas malformações congênitas. Revista Científica Multidisciplinar Núcleo do Conhecimento. Ano 05, Ed. 10, Vol. 06, pp. 62-86. Outubro de 2020. ISSN: 24480959, Link de acesso: https://www.nucleodoconhecimento.com.br/saude/anatomiado-pe

\section{RESUMO}

As malformações constituem alterações de estrutura, função ou metabolismo presentes ao nascer, que resultam em anomalias físicas ou mentais. A etiologia dessas malformações pode ser de origem genética, congênita ou ambiental. As malformações que acometem o aparelho locomotor causam grande transtorno estético, funcional e/ou emocional. Por isso, o exame físico do aparelho locomotor dos recém-nascidos é de extrema importância, pois a detecção precoce garantirá que o tratamento seja realizado antes da calcificação completa dos ossos. O objetivo desse

\footnotetext{
${ }^{1}$ Mestre em Ciências pelo programa de pós-graduação em Ciências Veterinárias da Universidade Federal Rural do Rio de Janeiro (2020). Graduada em Ciências Biológicas - Bacharelado (2017).

2 Professora Associada da Universidade Federal Rural do Rio de Janeiro (UFRRJ), Seropédica/RJ (2010-atual). Pesquisadora do Serviço de Ortopedia do Hospital Universitário Pedro Ernesto da Universidade do Estado do Rio de Janeiro (HUPE/UERJ), Rio de Janeiro/RJ (2010-atual). Docente de Anatomia Humana da ABEU Centro Universitário, Belford Roxo/RJ (2007-2010). Doutora em Ciências pela Faculdade de Medicina da Universidade de São Paulo (2009).
} 
artigo foi fazer uma breve descrição anatômica do pé e de seu desenvolvimento embrionário; e fazer uma revisão da literatura sobre as principais malformações congênitas que podem acometer essa região. $O$ tratamento dessas malformações pode ser cirúrgico ou não. Conforme o grau de acometimento e do impacto que a malformação causa na vida do paciente é necessário constituir uma equipe multidisciplinar. Sendo assim, o conhecimento das principais malformações congênitas que podem acometer os pés é de fundamental importância para o profissional de saúde.

Palavras-chave: Polidactilia, sinfalangismo, sindactilia, pé torto congênito, calcaneovalgo.

\section{INTRODUÇÃO}

As malformações constituem alterações de estrutura, função ou metabolismo presentes ao nascer, que resultam em anomalias físicas ou mentais. Essas podem ser simples ou múltiplas e de maior ou menor importância clínica, ou ainda, meramente estética (FEMBACH, 1998).

As consequências para os portadores de uma malformação são, muitas vezes, de ordem econômica, psíquica e social. Um recém-nascido que apresenta anomalia de um membro representa um desafio para seus pais e para a equipe de profissionais responsáveis pelo seu tratamento (FEMBACH, 1998; ABREU; SOUZA; OLIVEIRA, 2007).

A etiologia dessas malformações pode ser de origem genética ou congênita, quando acontecem durante o desenvolvimento intrauterino. Ainda existem os fatores teratogênicos ambientais: o abuso de álcool e de fumo e algumas doenças virais, como rubéola, toxoplasmose, sífilis, zika e citomegalovírus (ZAKERI et al., 2008).

As malformações que acometem o aparelho locomotor causam grande transtorno estético e funcional. Por isso, o exame físico do aparelho locomotor dos recémnascidos é de extrema importância, pois pode revelar muitas malformações que 
podem influenciar no seu desenvolvimento motor. A detecção precoce de problemas nos pés dos bebês é crucial para que o tratamento corretivo necessário seja realizado a tempo, de preferência antes da idade de aprender a andar (GORE; SPENCER, 2004).

Sendo assim, o conhecimento das principais anomalias que podem acometer os pés é de fundamental importância para o profissional de saúde: médico, enfermeiro ou fisioterapeuta. Com esse intuito, o objetivo desse artigo foi fazer uma breve descrição anatômica do pé e de seu desenvolvimento embrionário; e fazer uma revisão da literatura sobre as principais malformações congênitas que podem acometer essa região.

\section{REVISÃO ANATÔMICA DO PÉ}

O pé é formado pelos ossos do tarso, metatarso e as falanges (Figura 1). Existem sete ossos tarsais, cinco ossos metatarsais e 14 falanges (MOORE; DALLEY, 2007). 
Figura 1 - Ossos do pé direito, a. vista superior, b. vista plantar.

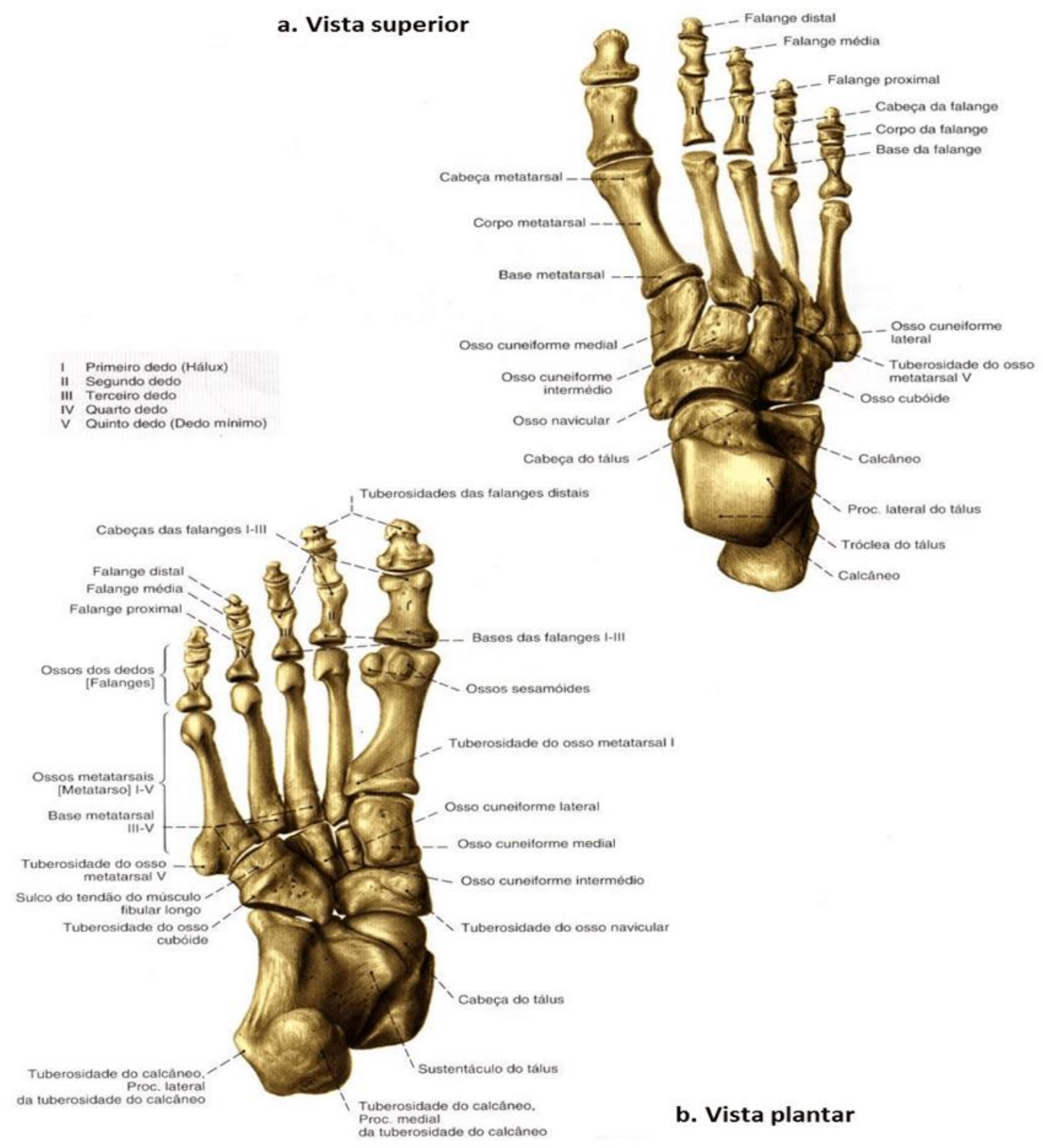

Fonte: Sobotta, 1995

O pé pode ser dividido em três regiões anatômicas: o retropé (tálus e calcâneo); meiopé (osso navicular, osso cuboide e os três ossos cuneiformes) e antepé (metatarsos e falanges) (Figura 2) (GORE; SPENCER, 2004). 
Figura 2 - Regiões anatômicas do pé: antepé, mediopé e retropé.

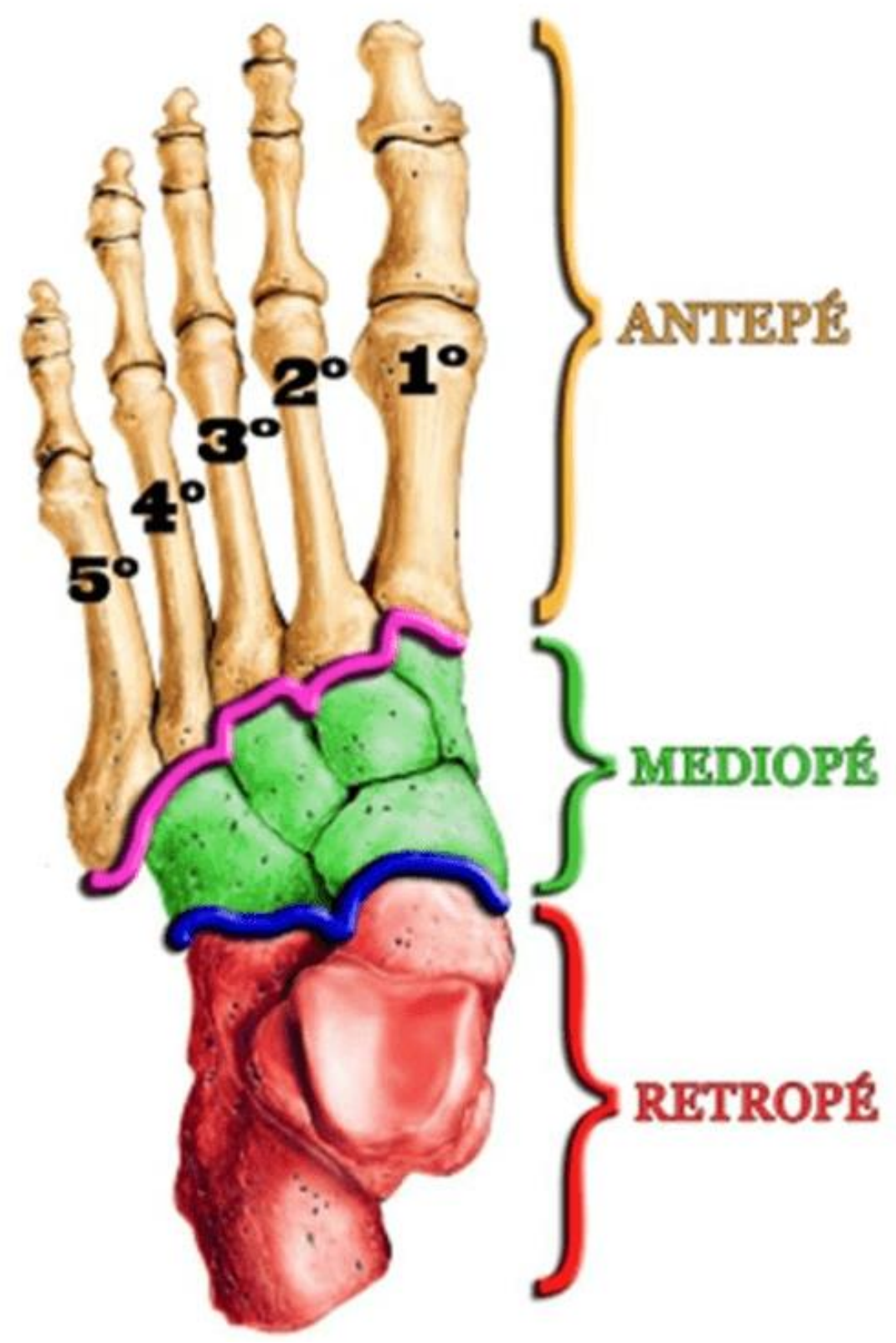

Fonte: https://www.pisadaideal.com.br/wp-content/uploads/2019/10/antemedioretro.

\subsection{TARSO}

O tarso forma a parte posterior ou proximal do pé e consiste em sete ossos: tálus, calcâneo, cuboide, navicular e três cuneiformes (Figura 3). Apenas um osso, o tálus, articula-se com os ossos da perna (MOORE; DALLEY, 2007). 
Figura 3 - Ossos do tarso e do metatarso.

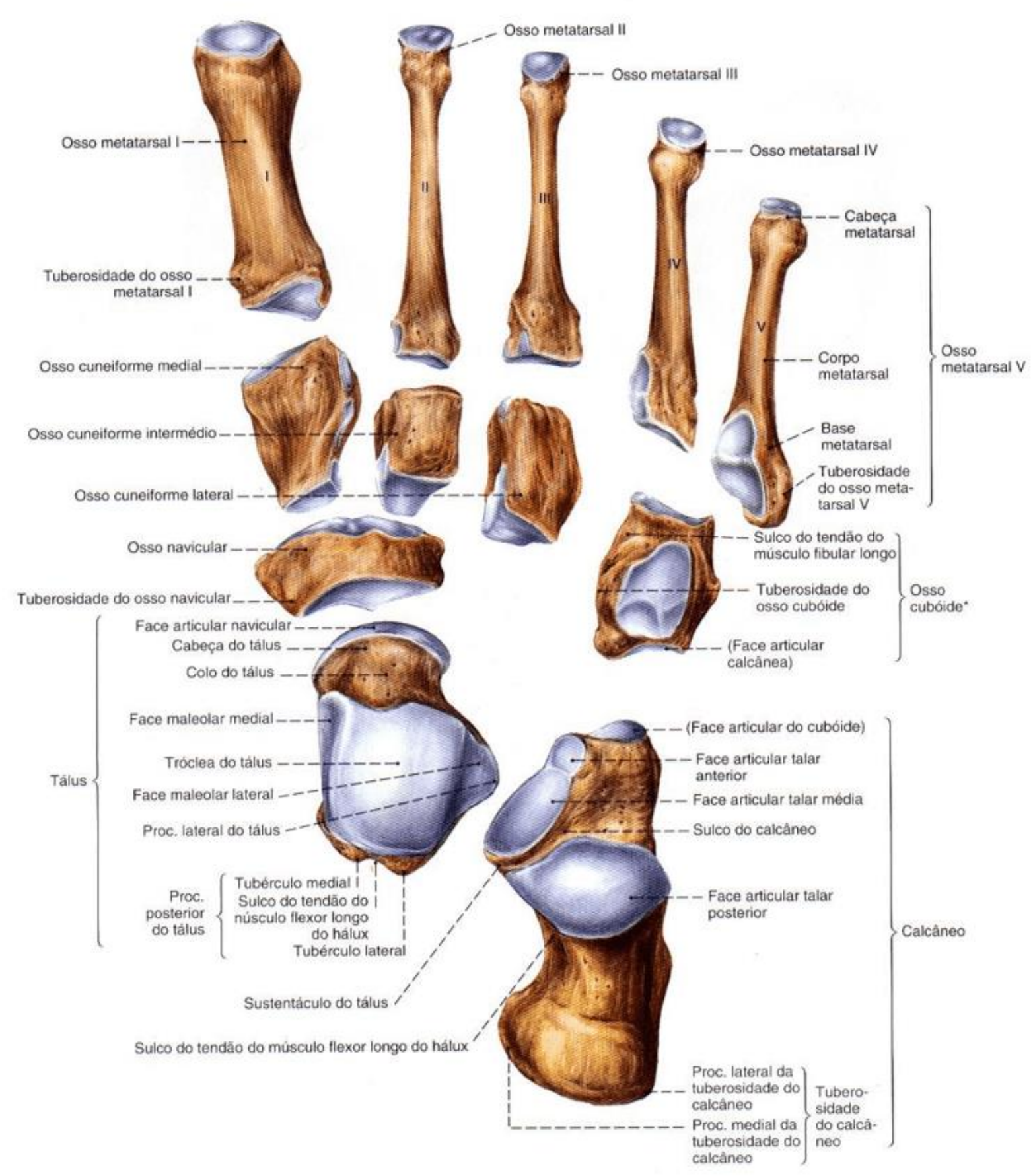

Legenda: *O osso cuboide foi representado em vista medial. Fonte: Sobotta, 1995. 
O tálus, que em latim significa tornozelo ou osso do tornozelo, possui corpo, colo e cabeça (Figura 3). A face superior, ou tróclea do tálus, está segura pelos dois maléolos e recebe o peso do corpo através da tíbia. Por sua vez, transmite esse peso, dividindo-o entre o calcâneo, sobre o qual está apoiado o corpo do tálus, e a parte anterior do pé, através de uma "rede" osteoligamentar que recebe a cabeça do tálus arredondada e direcionada ântero-medialmente. O tálus é o único osso tarsal que não possui fixações musculares ou tendíneas. A maior parte de sua superfície é coberta por cartilagem articular (MOORE; DALLEY, 2007).

calcâneo, em latim significa osso do calcanhar, é o maior e mais forte osso do pé (Figura 3). Na posição de pé, o calcâneo transmite a maior parte do peso do corpo do tálus para o solo. Os dois terços anteriores da superfície superior do calcâneo articulam-se com o tálus e a face anterior articula-se com o cuboide. A superfície lateral do calcâneo tem uma crista oblíqua, a tróclea fibular, que fixa uma roldana do tendão para os eversores do pé (músculos que afastam a planta do pé do plano mediano). Na face medial, o sustentáculo do tálus, o suporte do tálus semelhante a uma prateleira, projeta-se da margem superior da superfície medial do calcâneo e atua na sustentação da cabeça do tálus. A parte posterior do calcâneo tem uma proeminência grande, de sustentação de peso, a tuberosidade do calcâneo, que possui processos medial e lateral. Apenas o processo medial toca o solo na posição de pé (MOORE; DALLEY, 2007).

O navicular, que significa pequeno navio em latim, é um osso achatado, em forma de barco, situado entre a cabeça do tálus posteriormente e os três cuneiformes anteriormente (Figura 3). A face medial do navicular projeta-se inferiormente para formar a tuberosidade do navicular, um local importante para a fixação do tendão, porque a margem medial do pé não se apóia no solo, como faz a margem lateral. Em vez disso, forma um arco longitudinal do pé, que deve ser sustentado centralmente. Se essa tuberosidade for muito proeminente, pode pressionar contra a parte medial do sapato e causar dor no pé (MOORE; DALLEY, 2007).

O cuboide tem formato aproximadamente cúbico e é o osso mais lateral na fileira distal do tarso (Figura 3). Anteriormente à tuberosidade do cuboide, nas superfícies 
lateral e inferior do sulco, há um sulco do tendão do músculo fibular longo (MOORE; DALLEY, 2007).

Os três cuneiformes são o medial $\left(1^{\circ}\right)$, intermédio $\left(2^{\circ}\right)$ e lateral $\left(3^{\circ}\right)$ (Figura 3$)$. O cuneiforme medial é o maior osso e o cuneiforme intermédio é o menor. Cada cuneiforme, que em latim significa em forma de cunha, articula-se com o navicular posteriormente e com a base de seu metatarsal apropriado anteriormente. $\mathrm{O}$ cuneiforme lateral também se articula com o cuboide lateralmente (Figura 3) (MOORE; DALLEY, 2007).

\subsection{METATARSO}

O metatarso forma a parte anterior ou distal do pé e consiste em cinco ossos metatarsais numerados a partir da face medial do pé (Figuras 3 e 4). No esqueleto articulado do pé, as articulações tarsometatarsais formam uma linha tarsometatarsal oblíqua que une os pontos médios das margens medial e lateral mais curta do pé; assim os metatarsais e as falanges estão localizados na metade anterior e os tarsais estão na metade posterior (MOORE; DALLEY, 2007).

O 1ำ metatarsal é o mais curto e mais forte dos metatarsais. O 2ํㅡㄴ metarsal é o mais longo. Cada metatarsal tem uma base proximal, um corpo e uma cabeça distalmente. A base de cada metatarsal é a extremidade proximal, maior. As bases dos metatarsais articulam-se com os cuneiformes e o cuboide, e as cabeças articulam-se com as falanges proximais. As bases do $1^{\circ}$ e do $5^{\circ}$ metatarsais têm grandes tuberosidades que permitem fixação do tendão; a tuberosidade do $5^{\mathbf{0}}$ metatarsal projeta-se lateralmente sobre o cuboide. Na face plantar da cabeça do 1 - metatarsal há ossos sesamóides medial e lateral proeminentes incrustados nos seus tendões (MOORE; DALLEY, 2007). 
Figura 4 - Ossos do pé direito. a. vista proximal; b. vista plantar.
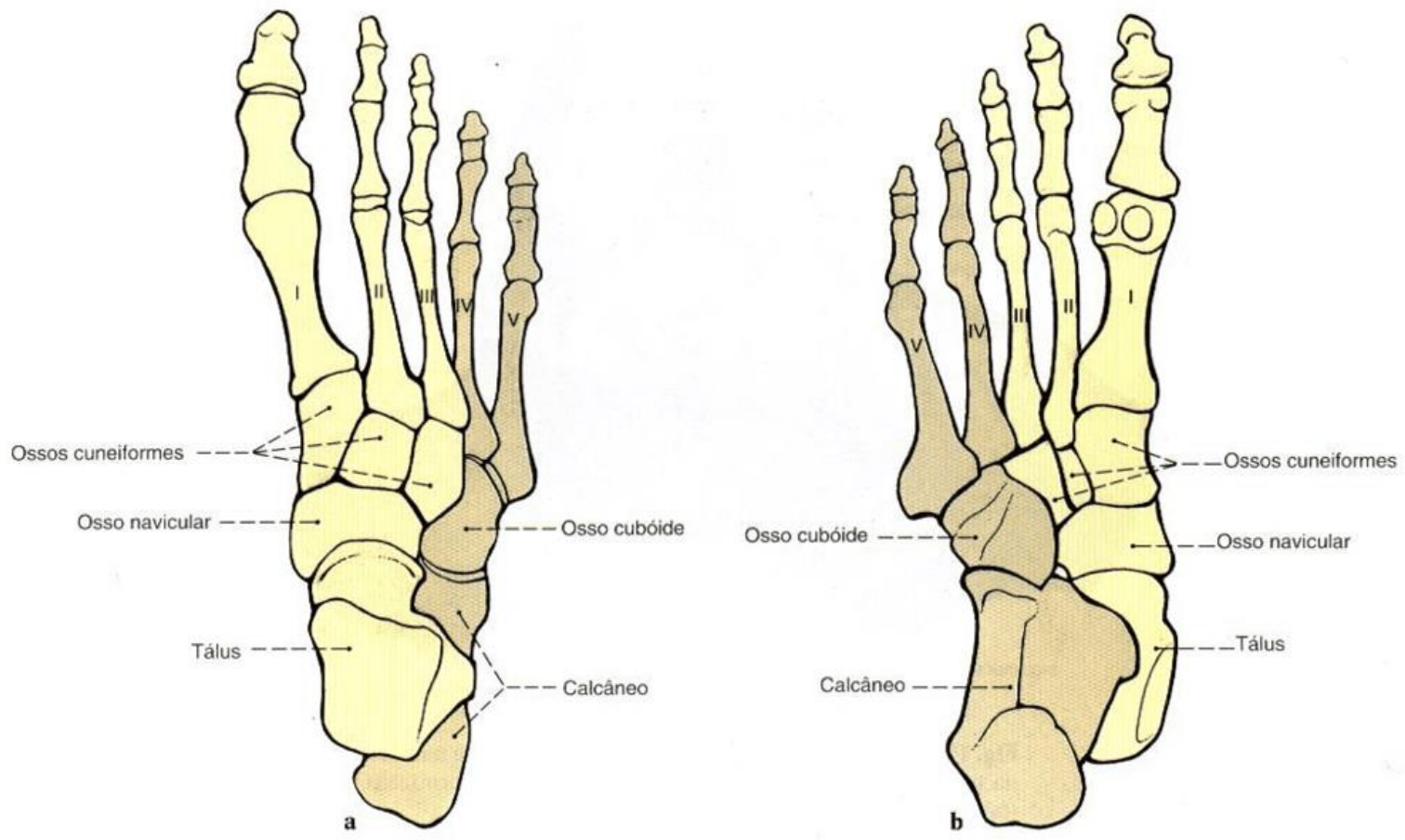

Fonte: Sobotta, 1995.

\subsection{FALANGES}

As 14 falanges são as seguintes: o hálux (1 dígito) tem duas falanges (proximal e distal); os outros quatro dígitos possuem três falanges cada: proximal, média e distal. Cada falange tem uma base (proximal), um corpo e uma cabeça (distal) (Figura 5). As falanges do $1^{\circ}$ dígito são curtas, largas e fortes. As falanges média e distal do $5^{\circ}$ dígito podem estar fundidas em pessoas idosas (MOORE; DALLEY, 2007). 
Figura 5 - Falanges do pé direito.
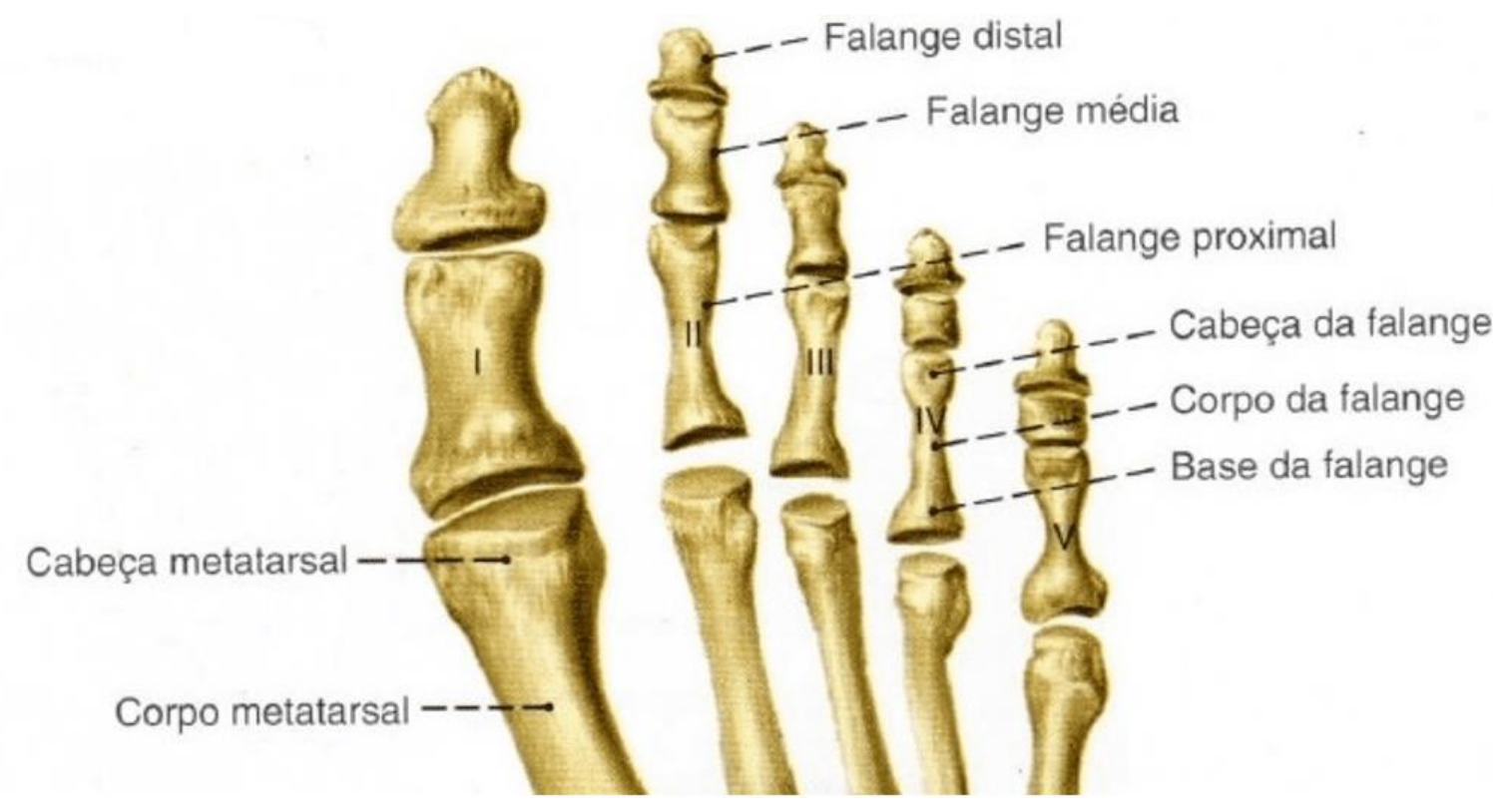

Fonte: Sobotta, 1995.

Os muitos ossos do pé formam uma unidade funcional que permite a distribuição do peso para uma larga plataforma a fim de manter o equilíbrio na posição de pé, a conformação e o ajuste às variações do terreno, absorvendo o choque. Eles também transferem o peso do calcanhar para a parte anterior do pé, conforme é necessário durante a marcha e a corrida (MOORE; DALLEY, 2007).

\section{DESENVOLVIMENTO EMBRIONÁRIO}

O desenvolvimento dos membros começa por volta da $4^{\mathrm{a}}$ semana de gestação, com a interação entre o ectoderma superficial e partes do mesoderma somático, que dá origem ao broto dos membros. Os brotos superiores e inferiores surgem com dois dias de diferença, sendo que o botão germinativo do membro superior aparece por volta do 26-27ํㅡㄹ dia pós-fertilização, enquanto o botão do membro inferior se desenvolve mais tarde, entre $28^{\circ}$ e $30^{\circ}$ dia. Na ponta de cada broto, o ectoderma forma a crista ectodérmica apical, uma estrutura com várias camadas epiteliais que interagem com o mesênquima (Figura 6). Essa interação vai fazendo com que o broto cresça para fora (LIMA; SCARFON, 2000). 


\section{MULTIDISCIPLINARY SCIENTIFIC JOURNAL

Figura 6 - Crista ectodérmica apical (em destaque colorido).

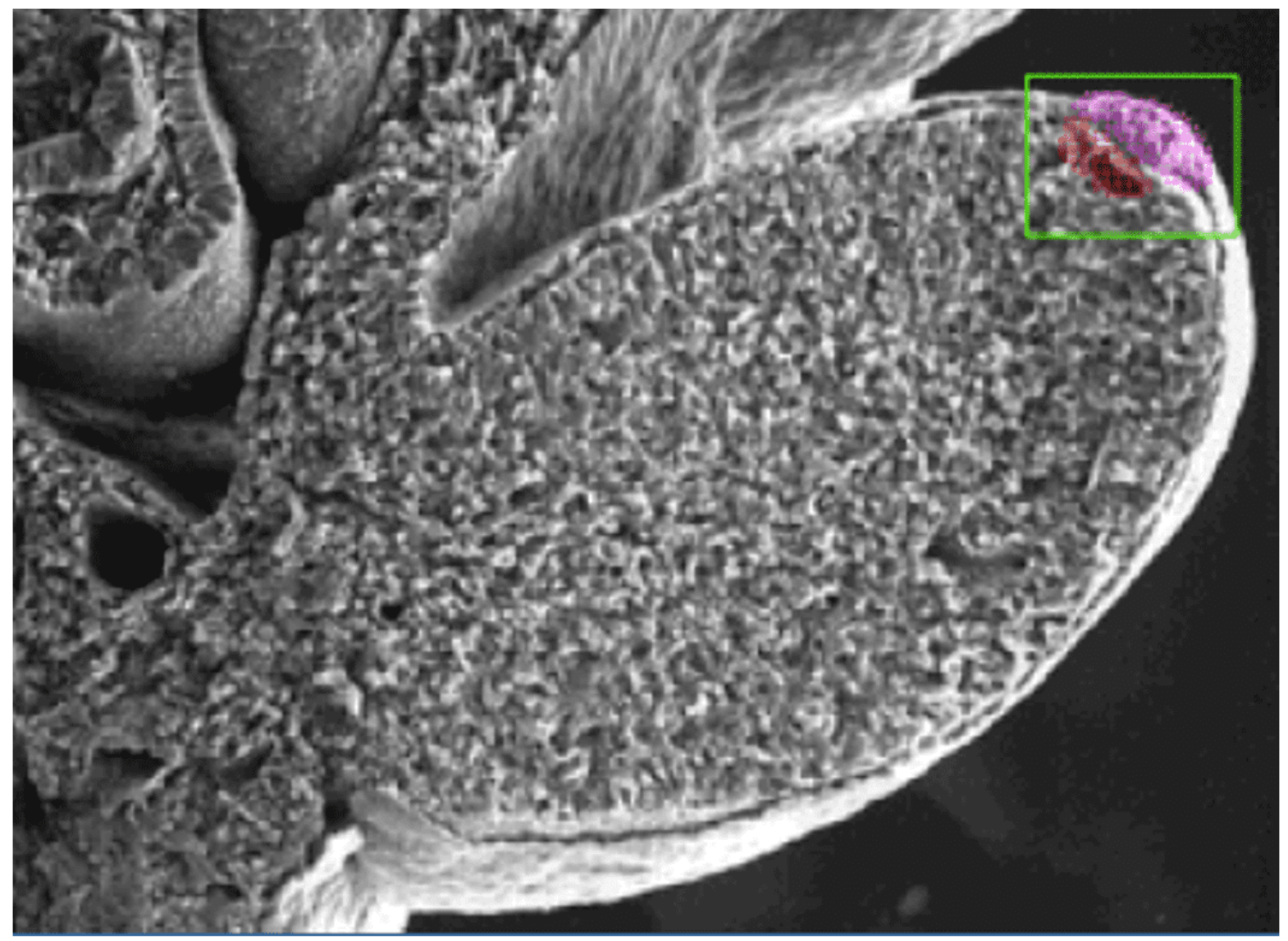

Fonte: Embryo Images, 2016.

Durante a quinta semana, são formadas as placas das mãos e dos pés e surgem os moldes mesenquimais dos ossos. Na sexta semana surgem os raios digitais nas mãos, formados por um esqueleto cartilaginoso. Durante a sétima semana os raios digitais são formados nos pés. Na ponta de cada raio digital surgem os primórdios dos ossos dos dígitos e se inicia a osteogênese nos ossos longos. A ossificação dos ossos do carpo começa no primeiro ano de vida. Ao final da oitava semana ocorre a apoptose que degenera o tecido das regiões interdigitais (Figura 7) (LIMA; SCARFON, 2000). 
Figura 7 - Desenvolvimento embrionário dos membros superiores e inferiores.

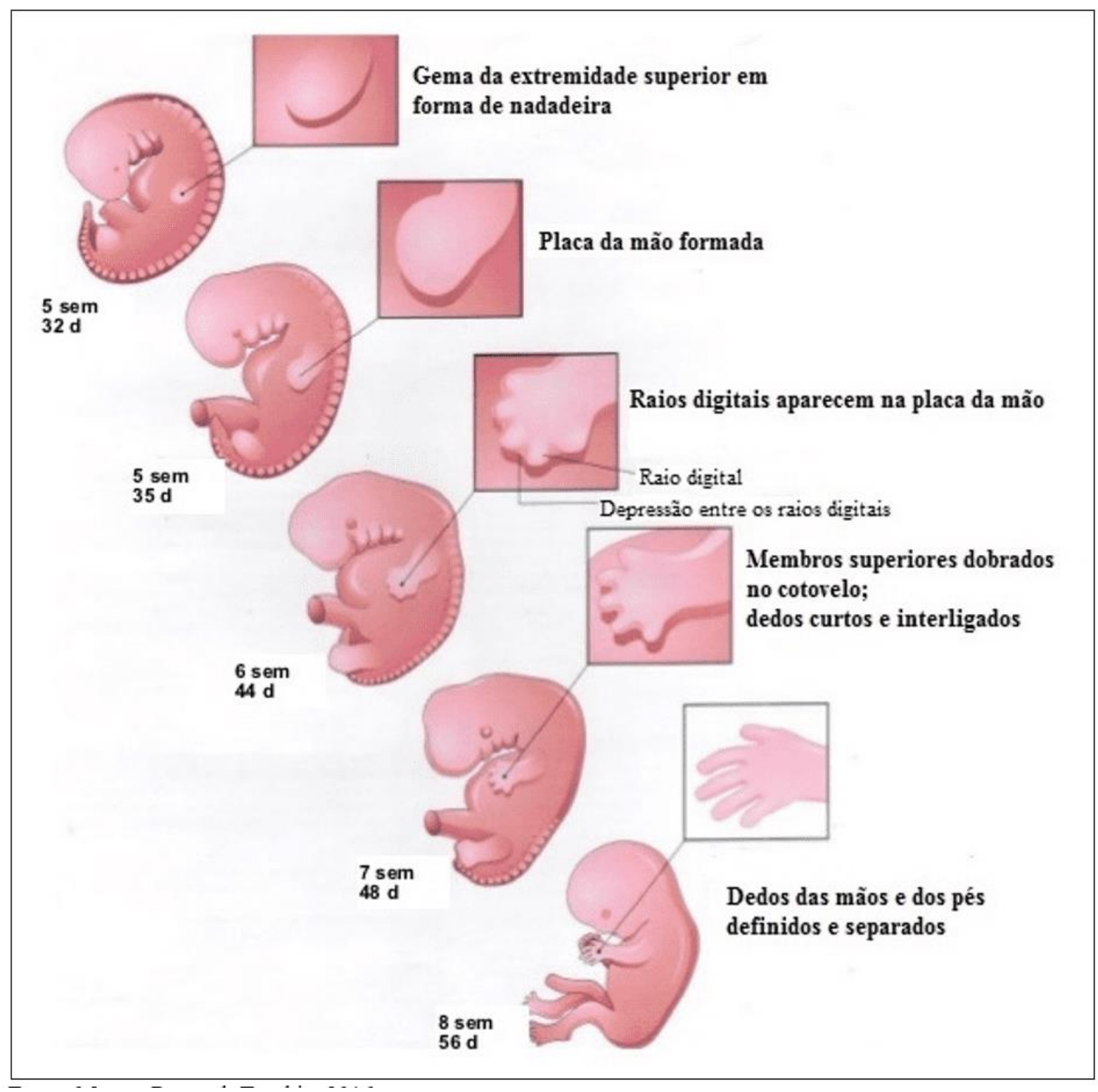

Fonte: Moore; Persaud; Torchia, 2016.

\section{MALFORMAÇÕES CONGÊNITAS DOS PÉS}

O espectro das malformações congênitas inclui uma variedade de defeitos que vão desde as mais simples até a ausência total do membro, sendo classificadas conforme o estágio do desenvolvimento na qual ocorreu a alteração, o processo que a provocou ou o resultado final. Essas alterações podem aparecer de forma isolada ou associadas (CHEN, 2007). 
As principais malformações congênitas dos pés são: metatarso aduto, pé torto congênito (talipes equinovarus), calcaneovalgo (talipes calcaneovalgus), pé talovertical, síndrome da banda amniótica e as deformidades dos dígitos: polidactilia, sindactilia, sinfalangismo e sobreposição dos dígitos (GORE; SPENCER, 2004).

\subsection{METATARSO ADUTO}

É um desvio aduto (interno) do antepé, de origem congênita, observado nos primeiros dias de vida do recém-nascido, podendo ser unilateral ou bilateral (STEDMAN, 1996). Os metatarsos afastam-se do eixo longitudinal principal do pé em direção à linha mediana, modificando a morfologia dos bordos interno e externo do pé, que assumem forma côncava e convexa, respectivamente (Figura 8) (GORE; SPENCER, 2004).

Figura 8 - Radiografia de um metatarso aduto com desvio medial de todos os metatarsos e relação normal entre o tálus e o calcâneo.
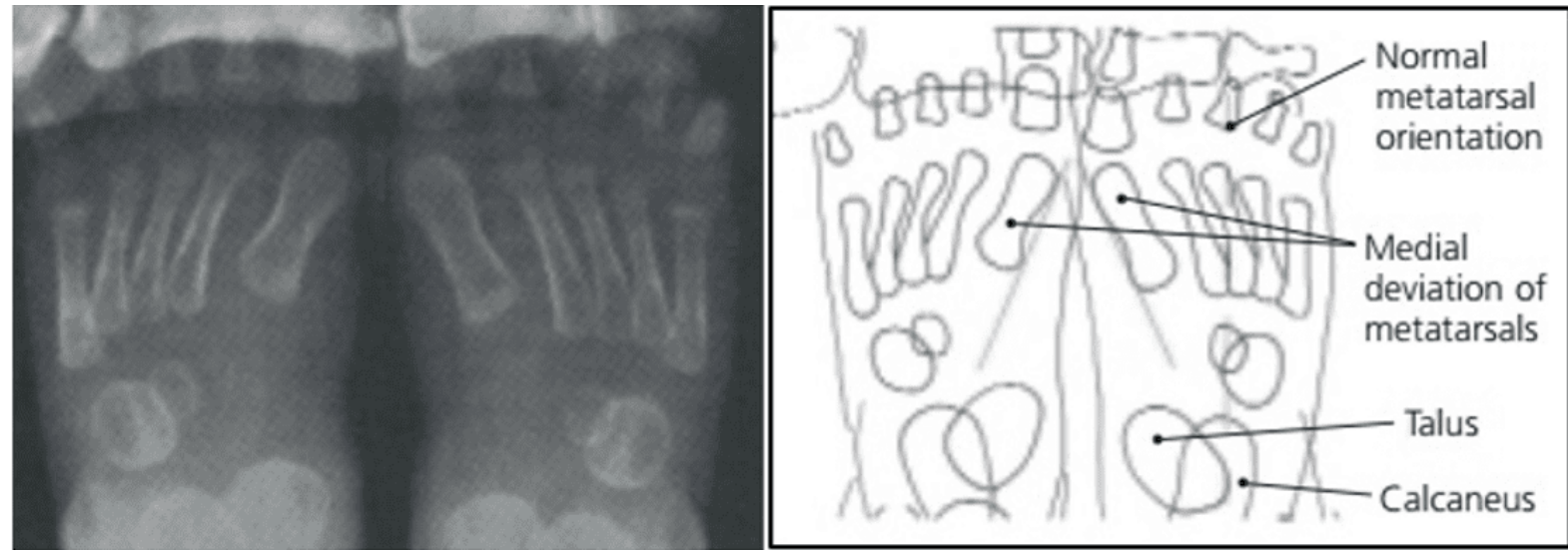

Fonte: Gore; Spencer, 2004.

Devido a essa diferença anatômica, o pé assume a forma da letra $C$ e pode ocorrer, ainda, uma prega cutânea profunda na borda medial do pé (Figura 9) (GORE; SPENCER, 2004). 
Figura 9 - Foto representativa de um metatarso aduto bilateral. Desenho esquemático de: (A) desvio medial do retropé; (B) borda lateral do pé arredondada em forma de C.
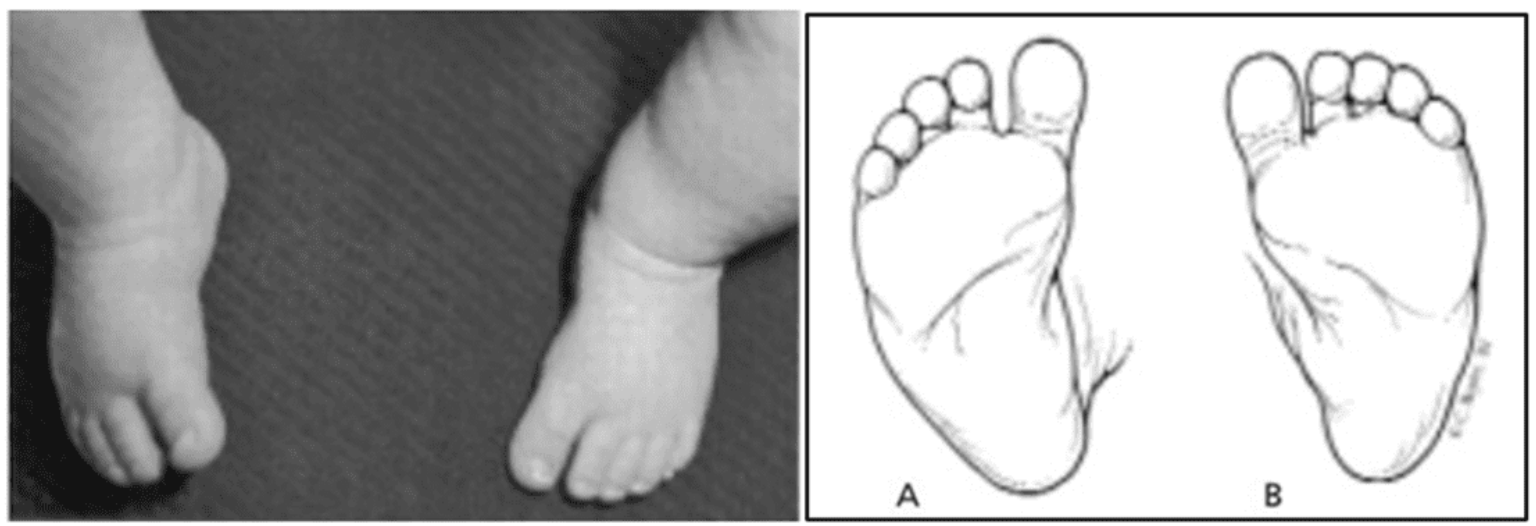

Fonte: Gore; Spencer, 2004.

A ocorrência do metatarso aduto é de 5:1000 nascidos vivos e sua causa ainda não foi esclarecida. No entanto, supõe-se que a posição do feto dentro do útero possa ocasionar essa condição, que não é grave e tende a se resolver naturalmente com o desenvolvimento da criança por volta dos 12 a 18 meses de idade (SKINNER; McMAHON, 2014).

\subsection{PÉ TORTO CONGÊNITO (TALIPES EQUINOVARUS)}

O pé torto refere-se a um pé torcido anormalmente, considerado como uma malformação congênita grave dos pés. O talipes equinovarus é o tipo mais comum $\mathrm{e}$ envolve a articulação talocalcânea (MOORE; DALLEY, 2007).

O pé é invertido, o tornozelo apresenta-se em flexão plantar e a parte anterior do pé é aduzida (voltada em direção à linha mediana de forma anormal). O pé assume a posição de um casco de cavalo, daí o prefixo "equino" (latim: equinus, cavalo) (Figura 10) (MOORE; DALLEY, 2007).

$\mathrm{Na}$ metade das pessoas afetadas, ambos os pés estão malformados. Uma pessoa com pé torto não corrigido não consegue colocar o calcanhar e a planta do pé em posição plana e sustenta o peso na superfície lateral da parte anterior do pé. Consequentemente, a marcha é dolorosa. A principal anormalidade é o encurtamento 
e a contração de músculos, tendões, ligamentos e cápsulas articulares na face medial e na face posterior do pé e do tornozelo (Figura 10) (MOORE; DALLEY, 2007).

Figura 10 - Desenho representativo do aspecto clínico de um pé torto congênito: flexão plantar do tornozelo, inversão e rotação interna do calcanhar, mesopé aduto e supinado.

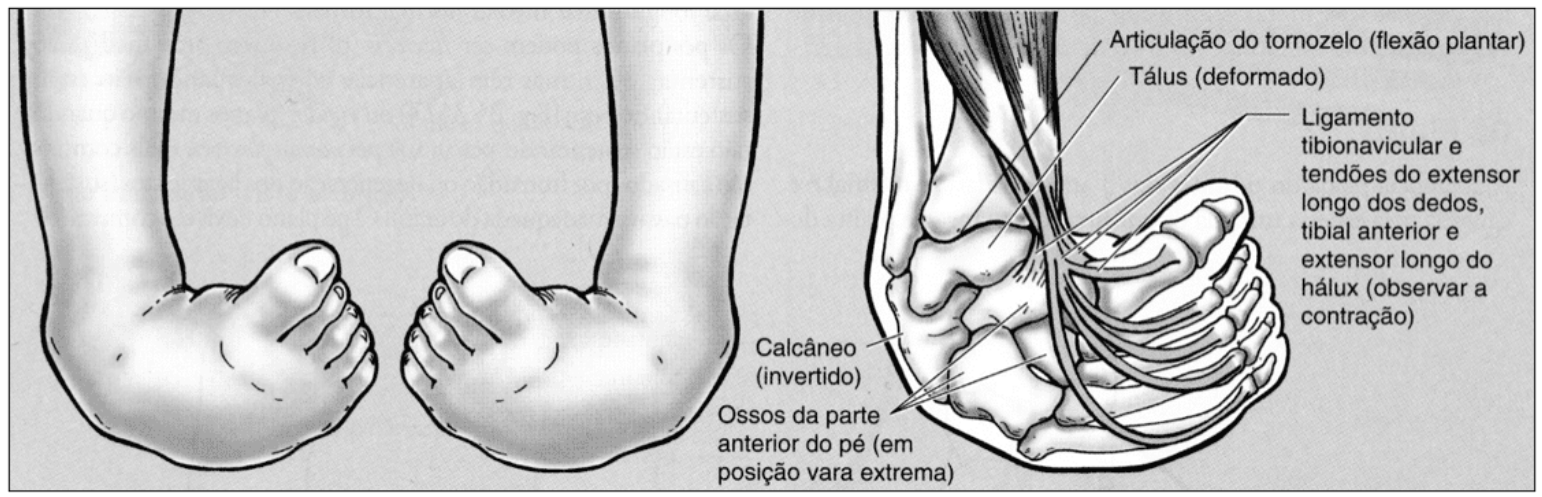

Fonte: Moore; Persaud; Torchia, 2016.

O pé torto ocorre em 2:1.000 nascidos vivos, sendo duas vezes mais comum no sexo masculino. No entanto, quando acomete meninas, os casos tendem a ser mais graves. O tratamento deve ter início nos primeiros dias após o nascimento e consiste no uso de aparelho gessado, órteses e tenotomia. Existem indícios de que o pé torto congênito é herdado geneticamente e pode estar associado a outras complicações do sistema musculoesquelético (SKINNER; McMAHON, 2014).

\subsection{CALCANEOVALGO (TALIPES CALCANEOVALGUS)}

O pé calcaneovalgo se caracteriza por sua flexão dorsal máxima, fazendo com que a face dorsal do pé entre em contato com a face anterior da perna (Figura 11). Consequentemente, as estruturas posteriores e anteriores do pé e da perna ficam comprometidas. Pode-se observar alongamento relativo das cápsulas, ligamentos, tendão do calcâneo e tendões fibulares e tibiais posteriores e um encurtamento das cápsulas, ligamentos, tendões extensores dos dígitos, do hálux e tibial anterior (SODRÉ, 2013). 
Figura 11 - a. Foto e b. Radiografia representativa de um pé calcaneovalgo esquerdo.
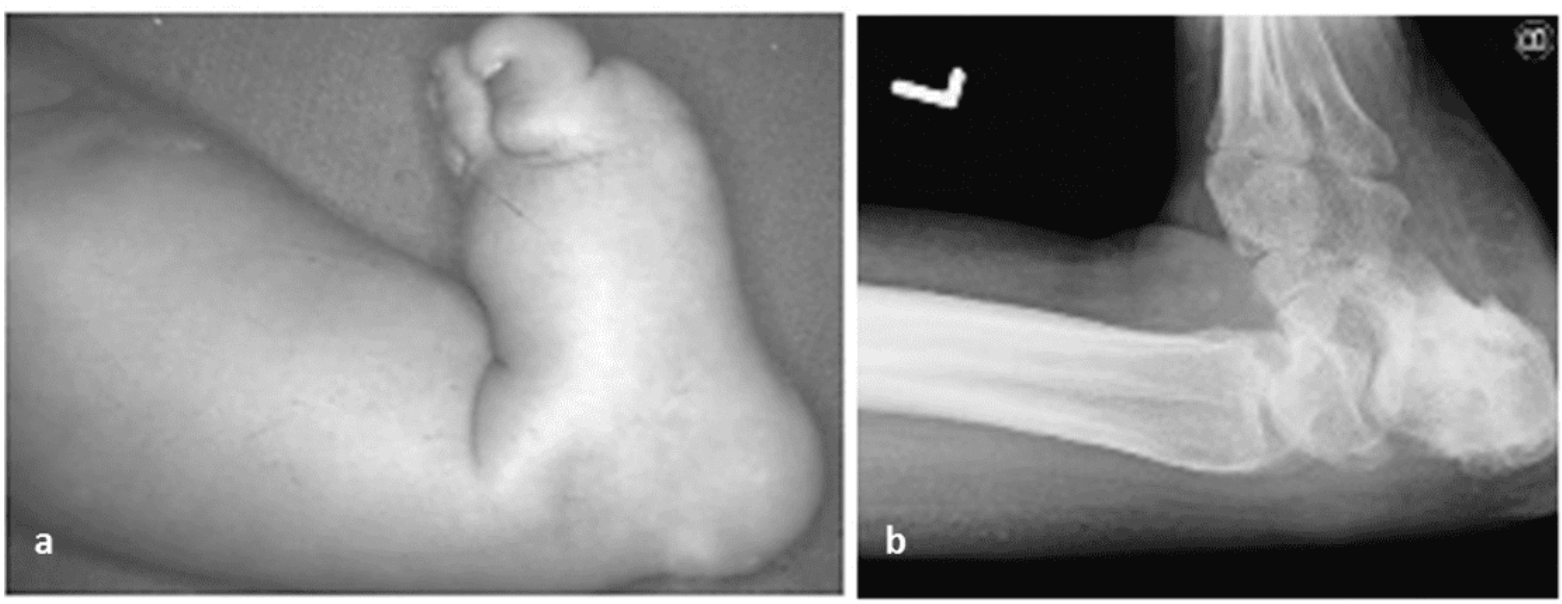

Fonte: a. Sodré, 2013; b. Chan; Khan, 2019.

Essa malformação ocorre em, aproximadamente, cinco por cento de todos os nascidos vivos e a incidência é maior no sexo feminino (GORE; SPENCER, 2004). De acordo com alguns autores, o calcaneovalgo tem um bom prognóstico e pode autocorrigir sem intervenção cirúrgica (HOFFINGER, 1996; WALL, 2000). Portanto, o tratamento deve começar o mais cedo possível e consiste, na maioria das vezes, de alongamentos realizados pela mãe durante a amamentação (GORE; SPENCER, 2004; SODRÉ, 2013).

\subsection{PÉ TALOVERTICAL}

O pé talovertical, também conhecido como pé convexo talovertical ou pé plano congênito, tem como principal característica sua rigidez. Apresenta convexidade plantar, dorsiflexão do antepé e equinismo do retropé. Pode ser distinta do pé calcaneovalgo através de exame radiográfico em perfil, uma vez que no pé talovertical o tálus permanece fixo mesmo com o pé em flexão plantar ou dorsal máxima (Figura 12). 
Figura 12 - a. Foto e b. Radiografia representativa de um pé talovertical direito.
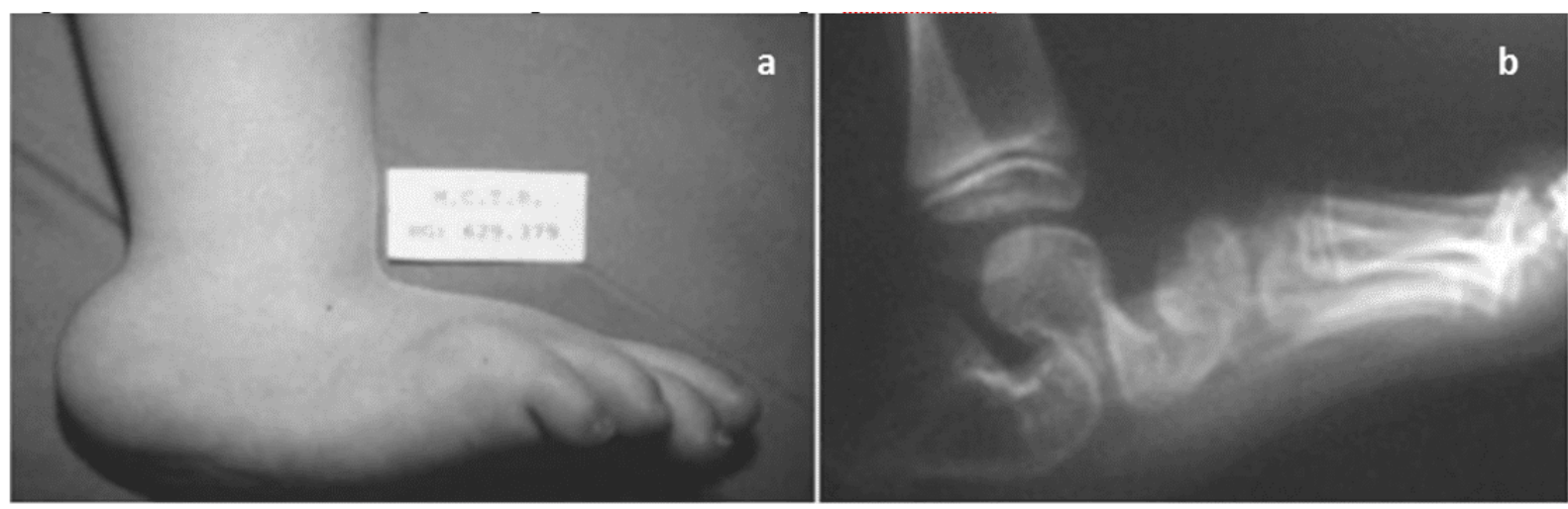

Fonte: Sodré, 2013.

Essa malformação acomete 1:10.000 nascidos vivos, de ambos os sexos, e metade dos casos está associada com outras desordens genéticas ou neuromusculares (McKIE; RADOMISLI, 2010). O prognóstico é ruim, pois os tratamentos conservadores com alongamentos são ineficazes (GORE; SPENCER, 2004) e a cirurgia pode aumentar a rigidez das articulações (SODRÉ, 2013).

\subsection{SÍNDROME DA BANDA AMNIÓTICA}

São bandas finas da membrana amniótica que se envolvem em torno do feto, causando desde anéis de constrições simples a grandes deformações e aborto espontâneo (Figura 13). Essas deformidades podem ser craniofaciais, viscerais e são muito frequentes nos membros inferiores. As manifestações clínicas mais comuns nesse caso são: atrofia distal, amputações intrauterinas congênitas, sindactilia e acrossindactilia, linfedema, luxação congênita do quadril, pseudoartrose da tíbia, pé torto congênito, metatarso varo e pé talovertical. A ocorrência de óbito e incompatibilidade com a vida é alta (NOGUEIRA et al., 2011). 
Figura 13 - Desenho esquemático da síndrome da banda amniótica.

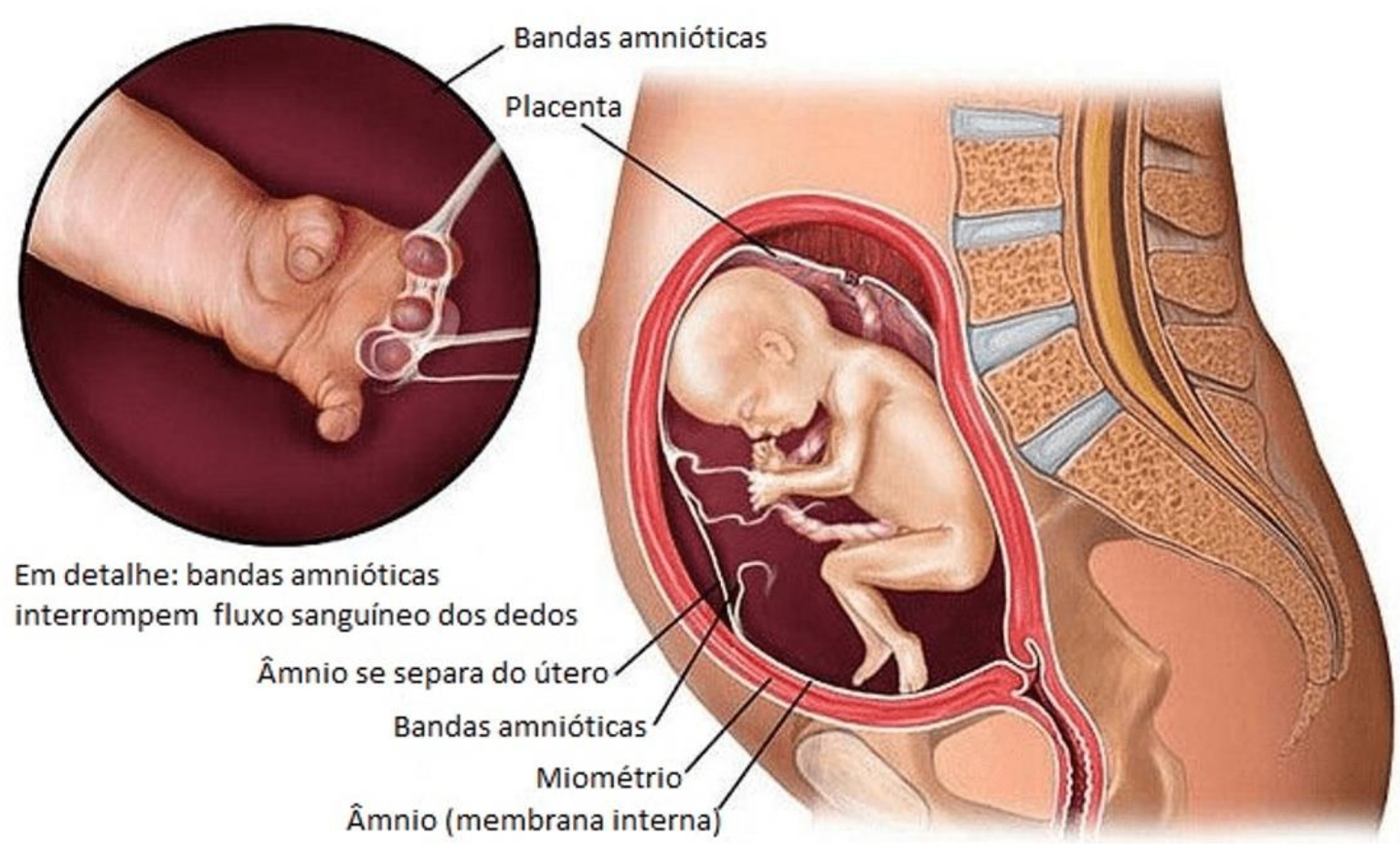

Fonte: Amniotic Band Syndrome, 2016.

Essa síndrome é rara, ocorrendo em 1:15.000 nascidos vivos (GORE; SPENCER, 2004). Sua causa é desconhecida, as duas hipóteses mais aceitas são a extrínseca, descrita em 1966 por Torpin e Faulkner; e a endógena, descrita em 1930 por Streeter. $\mathrm{Na}$ vertente extrínseca, os pesquisadores atestaram a ruptura precoce do âmnio, causando sua aderência ao corpo do feto e posterior constrição das áreas envolvidas. Já na teoria endógena, o problema ocorreria ainda na fase da gastrulação, quando uma ruptura na estrutura vascular do embrião alteraria a gênese da membrana amniótica (NOGUEIRA et al., 2011).

O tratamento visa a liberar as bandas amnióticas envoltas no feto o mais breve possível, podendo ser realizado, inclusive, por meio de endoscopia intrauterina. Associadas ao tratamento, as zetaplastias, múltiplas ou únicas, conferem um bom prognóstico para o paciente (NOGUEIRA et al., 2011). 


\subsection{DEFORMIDADES DOS DÍGITOS}

As deformidades mais comuns dos dígitos são: polidactilia, sindactilia, sinfalangismo e sobreposição dos dígitos.

\subsubsection{POLIDACTILIA}

É definida pela presença de um ou mais dígitos nas mãos ou nos pés, além dos cinco dígitos presentes em condições normais. Isso ocorre devido a uma falha na apoptose das células da crista ectodérmica apical no broto dos membros durante o desenvolvimento embrionário. A prevalência da polidactilia é de 0,3 a 3,6 em cada 1.000 nascidos vivos. Os homens são mais acometidos do que as mulheres e os negros mais afetados do que os brancos (McDANIEL; TAFURI, 1996; MALIK, 2014).

A causa pode ser genética, como herança dominante autossomal com penetrância variável, envolvendo, preferencialmente, os dígitos laterais e mediais, especialmente o quinto dígito. Nos casos mais simples, pode acontecer apenas a duplicação da falange distal e nos mais complexos, ocorre a duplicação completa do dígito, incluindo unhas, tendões e estruturas vasculares e nervosas (GORE; SPENCER, 2004).

A classificação de Temtamy e McKusick, descrita em 1969, é uma das mais utilizadas na literatura para descrever os tipos de polidactilia e está dividida em pré-axial, axial e pós-axial, com suas subdivisões listadas no Quadro 1 (LIMA; SCARFON, 2000).

Quadro 1 - Classificação de Temtamy e McKusick para polidactilia.

\begin{tabular}{|c|c|}
\hline Polidactilia & $\begin{array}{l}\text { Tipo } 1 \text { (polegar ou hálux): duplicação parcial ou } \\
\text { completa do polegar ou do hálux, sem sindactilia. }\end{array}$ \\
\hline pre-axial & $\begin{array}{l}\text { Tipo } 2 \text { (polidactilia do polegar): presença de três falanges no } \\
\text { polegar. }\end{array}$ \\
\hline & $\begin{array}{l}\text { Tipo } 3 \text { (polidactilia do dígito indicador): duplicação do } \\
\text { indicador, com ou sem polegar adicional bi ou tri falângico. }\end{array}$ \\
\hline
\end{tabular}




\begin{tabular}{|c|c|}
\hline & $\begin{array}{l}\text { Nos pés, pode ocorrer a duplicação do cuneiforme e do } \\
\text { primeiro metacarpo. }\end{array}$ \\
\hline & $\begin{array}{l}\text { Tipo } 4 \text { (polisindactilia): polegar ou hálux com raios } \\
\text { duplicados e sindactilizados. A aparência do dígito é larga, } \\
\text { com unha bífida e a falange distal pode se apresentar } \\
\text { radialmente desviada. }\end{array}$ \\
\hline 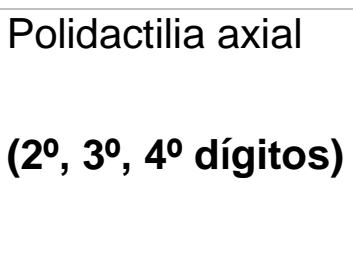 & $\begin{array}{l}\text { Frequentemente acompanhada de sindactilia bilateral. A } \\
\text { duplicação do } 2^{\circ} \text { dígito é rara, correspondendo a } 3 \% \text { dos } \\
\text { casos; já a duplicação do } 3^{\circ} \text { ou } 4^{\circ} \text { dígito é mais comum, com } \\
\text { ocorrência maior no dedo anelar. }\end{array}$ \\
\hline $\begin{array}{l}\text { Polidactilia } \\
\text { pós-axial }\end{array}$ & $\begin{array}{l}\text { Tipo A: dígito duplicado é completo e articulado com a borda } \\
\text { medial do } 5^{\circ} \text { metacarpo/tarso, esse ainda pode se } \\
\text { apresentar bífido ou duplicado. }\end{array}$ \\
\hline (após o 5 dígito) & $\begin{array}{l}\text { Tipo B: o dígito extra é rudimentar, muitas vezes } \\
\text { representado por uma projeção de tecido mole ou estrutura } \\
\text { pedunculada contendo falange distal e unha, situadas na } \\
\text { borda medial do } 5^{\circ} \text { dígito. }\end{array}$ \\
\hline
\end{tabular}

Fonte: LIMA; SCARFON, 2000.

Além da classificação de Temtamy e McKusick, outras classificações são muito utilizadas nos estudos de polidactilia, como a de Venn-Watson e a de Watanabe (LIMA; SCARFON, 2000; BELTHUR; LINTON; BARNES, 2011).

Venn-Watson, em 1976, introduziu uma classificação morfológica baseada na configuração anatômica dos metatarsos e das partes ósseas duplicadas. Reconheceu seis variações: metatarso normal com duplicação distal, 1ำ metatarso em bloco, metatarso em forma de $\mathrm{Y}$, metatarso em forma de $\mathrm{T}$, metatarso com eixo normal e cabeça ampla, e duplicação do raio (Figura 14) (BELTHUR; LINTON; BARNES, 2011). 
Figura 14 - Desenho esquemático da classificação Venn-Watson para polidactilia do pé.

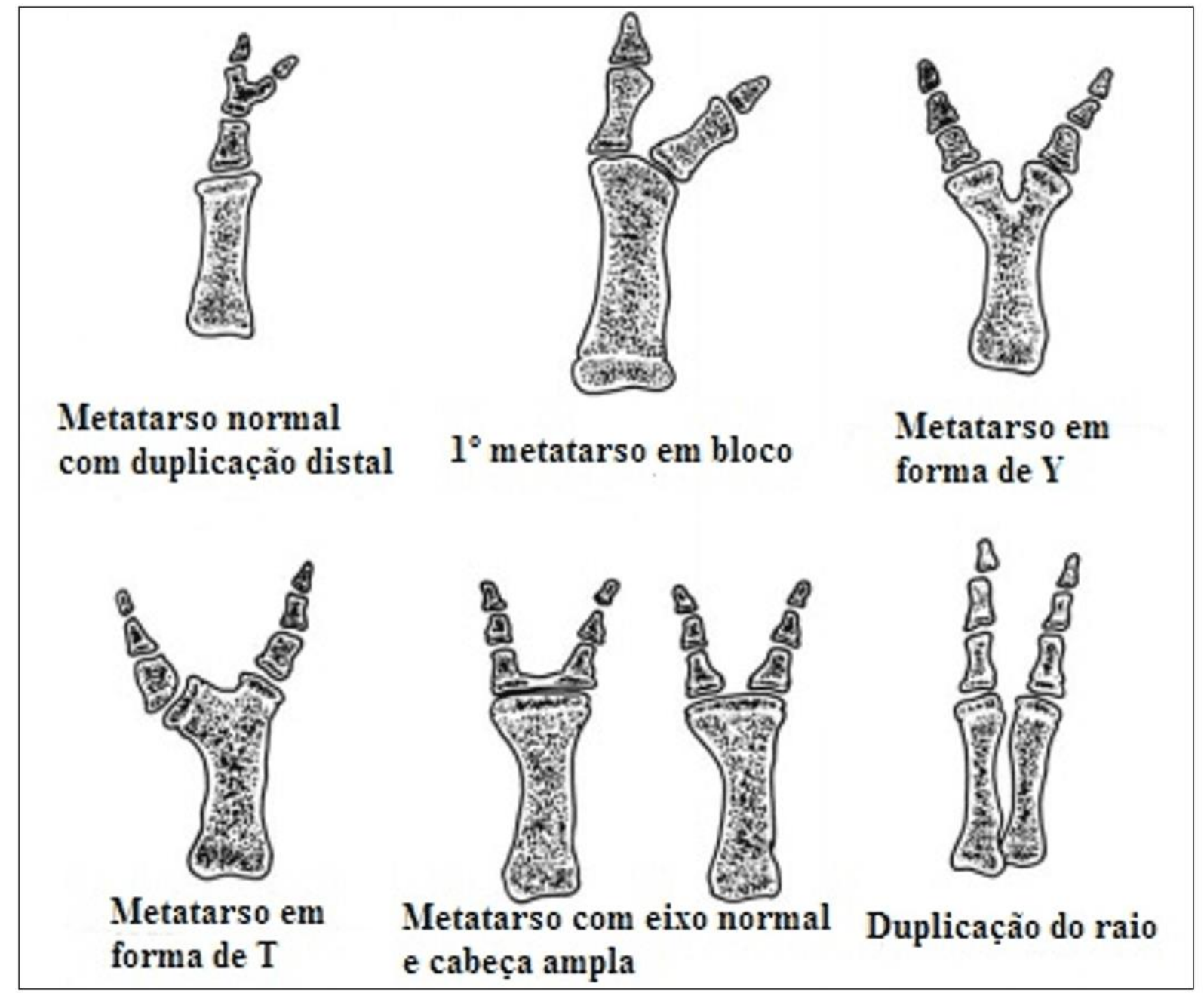

Fonte: Belthur; Linton; Barnes, 2011.

Watanabe et al., (1992), criaram sua própria classificação morfológica, baseados no envolvimento dos raios e níveis de duplicação. Segundo os autores, a polidactilia do pé pode ser dividida em três grandes grupos: raio medial, raio central e raio lateral, sendo cada grupo subdividido em tarsal, metatarsal, falangeal proximal, falangeal médio e falangeal distal (Figura 15) (BELTHUR; LINTON; BARNES, 2011). 
Figura 15 - Desenho esquemático da classificação Watanabe para polidactilia préaxial do pé.

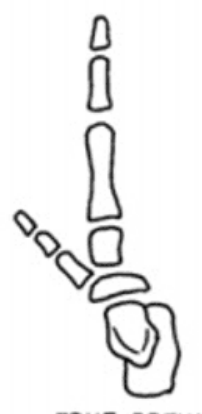

TRUE PREHALLUX

TARSAL TYPE

$3 x$

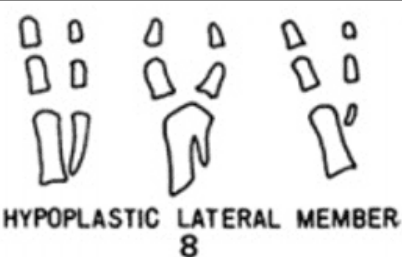

(.) 0<smiles>C=CC=CC</smiles>

HIGHLY DEFORMED HYPOPLASTIC

BOTH METATARSALS MEDIAL MEMBER

MEtATARSAL TYPE
DUPLICATION
WITH BLOCK
METATARSAL
7

\section{0}<smiles>[194In]</smiles><smiles>C1=CCCCC1</smiles>

COMPLETE

DUPLICATION

WITH NORMAL

METATARSAL

3

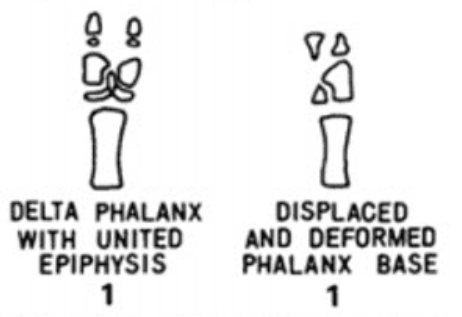

PROXIMAL PHALANGEAL TYPE

$36 \%$

1

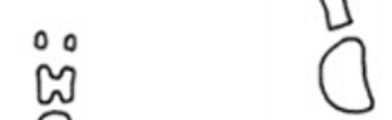

00

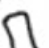

COMPLETE

DUPLICATION

WITH BLOCK

METATARSAL

PHALANX

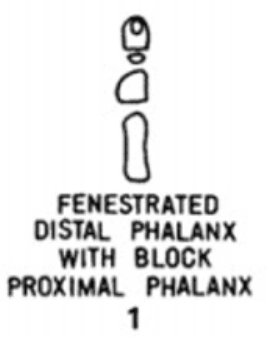

DISTAL PHALANGEAL TYPE

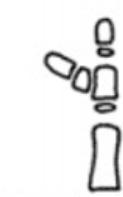

LARGE EPIPHYSIS

ARTICULATING

WITH THE SIDE

OF PROXIMAL

PHALANX

M 10

प)

வ

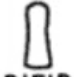

BIFID

DISTAL

PHALANX

$\circ 0$<smiles>[C-]1=CCC1</smiles>

NONARTICULATED

MEDIAL MEMBER 2

$22 \%$

MEDIAL RAY POLYDACTYLY

(22 patients, 36 feet)

Fonte: Belthur; Linton; Barnes, 2011.

\subsubsection{SINDACTILIA}

Sindactilia é a fusão entre dois ou mais dígitos das mãos ou dos pés, que pode ocorrer tanto em partes moles, de fácil solução cirúrgica, como pode ser uma fusão óssea (sinostose), mais complicada. Ocorre devido a uma falha na necrose interdigital 
longitudinal durante o desenvolvimento intrauterino. Esta condição é transmitida como traço autossômico dominante em muitas famílias (MANDARANO-FILHO et al., 2013).

Sua incidência é de, aproximadamente, 1:2.500 nascidos vivos, sendo geralmente bilateral e simétrica (McDANIEL; TAFURI, 1996). A incidência nas mãos é de 3:100.000 e nos pés de 12:100.000. Acomete mais homens do que mulheres na proporção de 2:1. É incomum em negros (MANDARANO-FILHO et al., 2013). A sindactilia entre o terceiro e quarto dígitos são comuns, sendo raros os casos que envolvem o primeiro e segundo dígitos (Figura 16) (RUSCHEL; LECH, 2003).

Figura 16 - Sindactilia simples incompleta entre $2^{\circ}$ e $3^{\circ}$ dígitos bilateral.

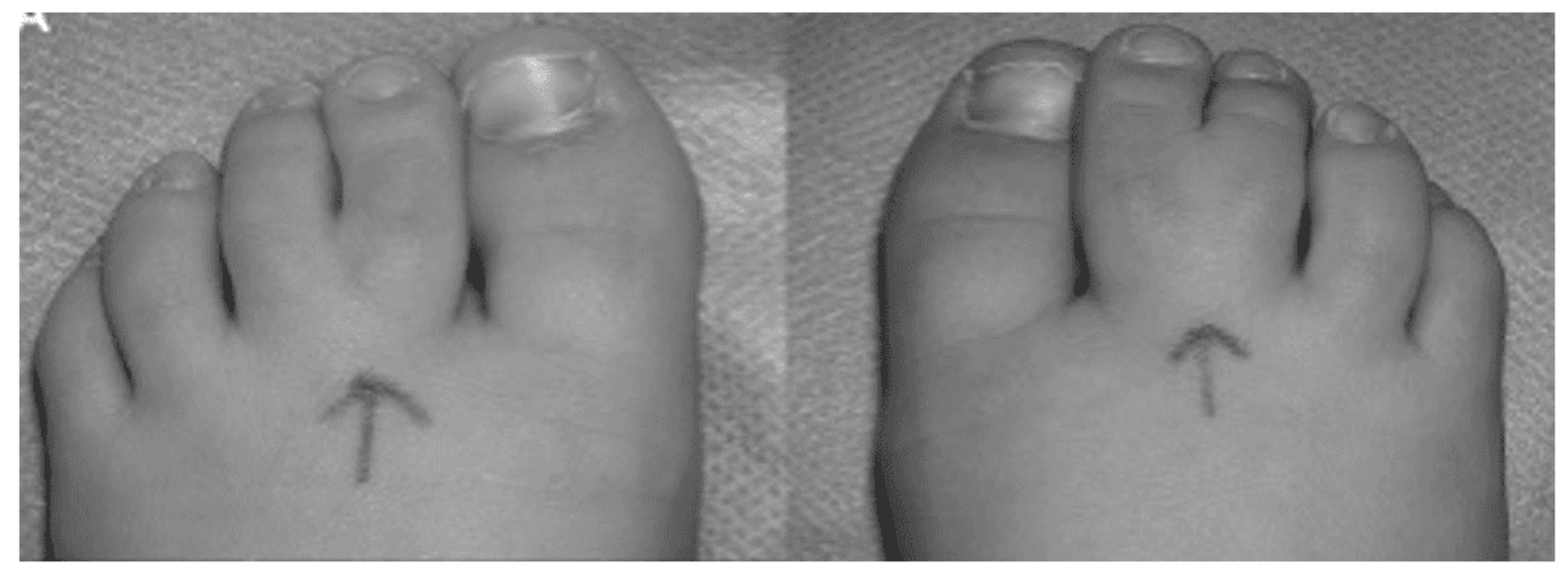

Fonte: Marsh; Floyd, 2011.

Segundo Mandarano-Filho et al. (2013), a sindactilia pode ser classificada como simples ou complexa, de acordo com o Quadro 2.

Quadro 2 - Classificação de Mandarano-Filho para sindactilia.

\begin{tabular}{|l|l|}
$\begin{array}{l}\text { Simples: somente pele une os } \\
\text { dígitos. }\end{array}$ & $\begin{array}{l}\text { Completa: união não deixa espaço entre } \\
\text { os dígitos. }\end{array}$ \\
& $\underline{\text { Incompleta: dígitos estão conectados em }}$ \\
& $\begin{array}{l}\text { qualquer outro ponto entre a comissura } \\
\text { normal e o dígito distal. }\end{array}$ \\
\hline
\end{tabular}


Complexa: a fusão dos dígitos também envolve ossos, tendões e estruturas vasculonervosas.

Fonte: Mandarano-Filho et al. (2013).

\subsubsection{SINFALANGISMO}

Sinfalangismo é uma malformação congênita rara caracterizada pela fusão das articulações dos dígitos das mãos ou dos pés. Pode haver acometimento funcional das ações de preensão e de pinça do membro afetado (CASE; HEILMAN, 2005).

A condição foi primeiramente descrita por Harvey Cushing, em 1916, que relatou uma família com fusão hereditária das articulações interfalângicas proximais da mão. A marca característica é a fusão óssea longitudinal em toda a articulação (CUSHING, 1916).

De acordo com Baek e Lee (2012) o sinfalangismo é classificado em 3 graus de acordo com o Quadro 3 e Figura 17.

Quadro 3 - Classificação de Baek e Lee para sinfalangismo.

\begin{tabular}{l|l|}
\hline Grau I & $\begin{array}{l}\text { Sinfalangismo fibroso (pequeno espaço articular, limitado na } \\
\text { articulação interfalangeal distal) }\end{array}$ \\
\hline Grau II & $\begin{array}{l}\text { Sinfalangismo cartilaginoso (apenas uma fenda do espaço interfalangeal } \\
\text { pode ser observada) }\end{array}$ \\
\hline $\begin{array}{l}\text { Grau } \\
\text { III }\end{array}$ & Sinfalangismo ósseo \\
\hline
\end{tabular}

Fonte: Baek e Lee (2012).

Figura 17 - Graus de sinfalangismo de acordo com a classificação de Baek e Lee visualizados em uma radiografia simples. (A) Articulação normal. (B) Grau I: sinfalangismo fibroso - pequeno espaço articular, limitado na articulação interfalangeal 
distal. (C) Grau II: sinfalangismo cartilaginoso - apenas uma fenda do espaço interfalangeal pode ser observada. (D) Grau III: sinfalangismo ósseo.
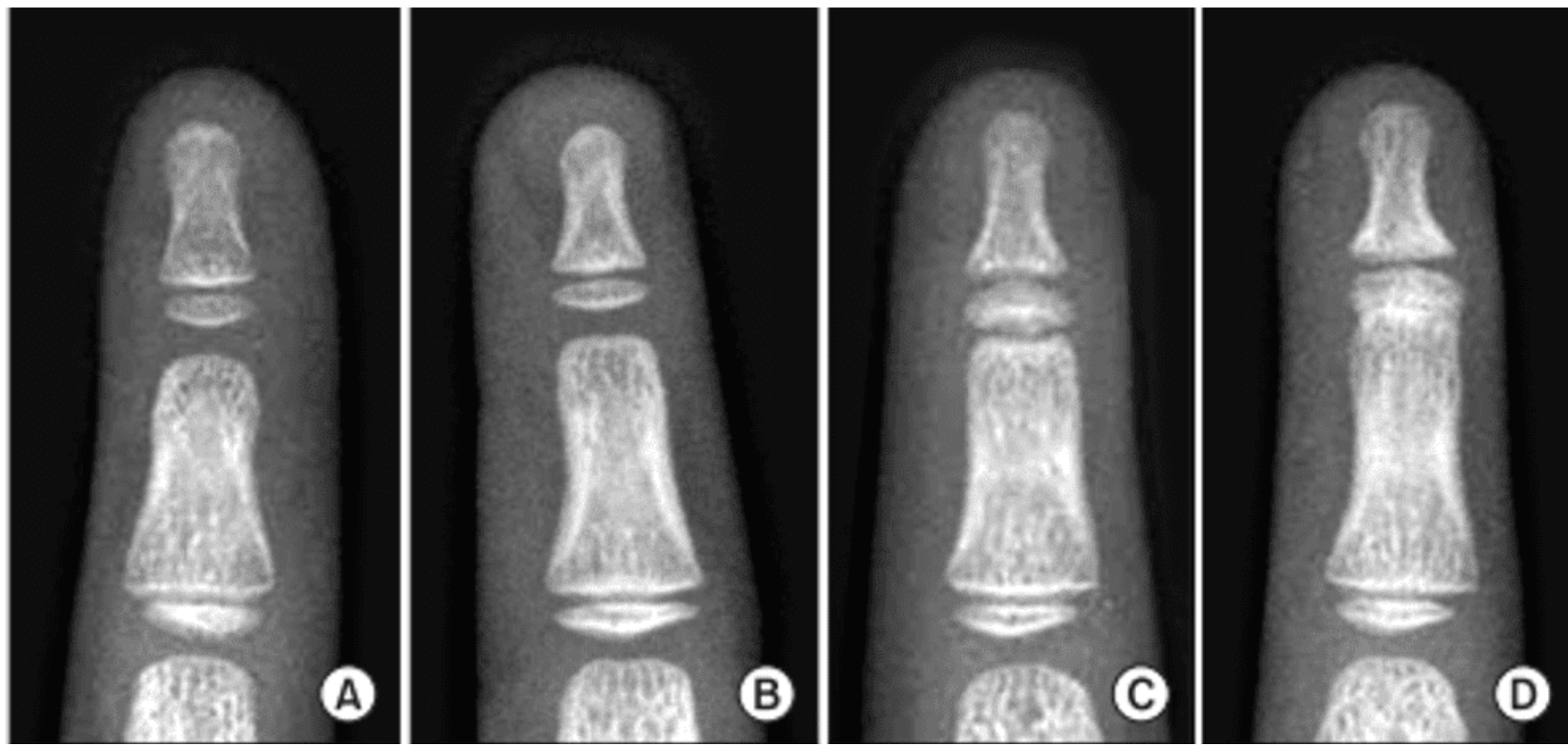

Fonte: Baek; Lee, 2012.

O Quadro 4 mostra a classificação de Flatt e Wood (1975) para sinfalangismo.

Quadro 4 - Classificação de Flatt e Wood para sinfalangismo.

\begin{tabular}{|l|l|}
\hline Sinfalangismo verdadeiro & $\begin{array}{l}\text { Dígitos envolvidos têm tamanhos } \\
\text { normais }\end{array}$ \\
\hline Simbraquidactilia & Dígitos afetados são curtos e rígidos \\
\hline $\begin{array}{l}\text { Sinfalangismo com outras anomalias } \\
\text { associadas }\end{array}$ & $\begin{array}{l}\text { Por exemplo: síndrome de Apert ou } \\
\text { síndrome de Poland }\end{array}$ \\
\hline
\end{tabular}

Fonte: Flatt e Wood (1975).

\subsubsection{SOBREPOSIÇÃO DOS DÍGITOS}

A sobreposição dos dígitos ocorre quando um dígito fica por cima de outro. A manifestação mais comum é no quinto dígito, que se apresenta aduzido e com alguma rotação externa, posicionando-se acima do quarto dígito (Figura 18) (GORE; SPENCER, 2004). 
Figura 18 - a. Desenho representativo de uma sobreposição do quinto dígito sobre o quarto. b. Fotografia de uma sobreposição do segundo dígito sobre o primeiro.

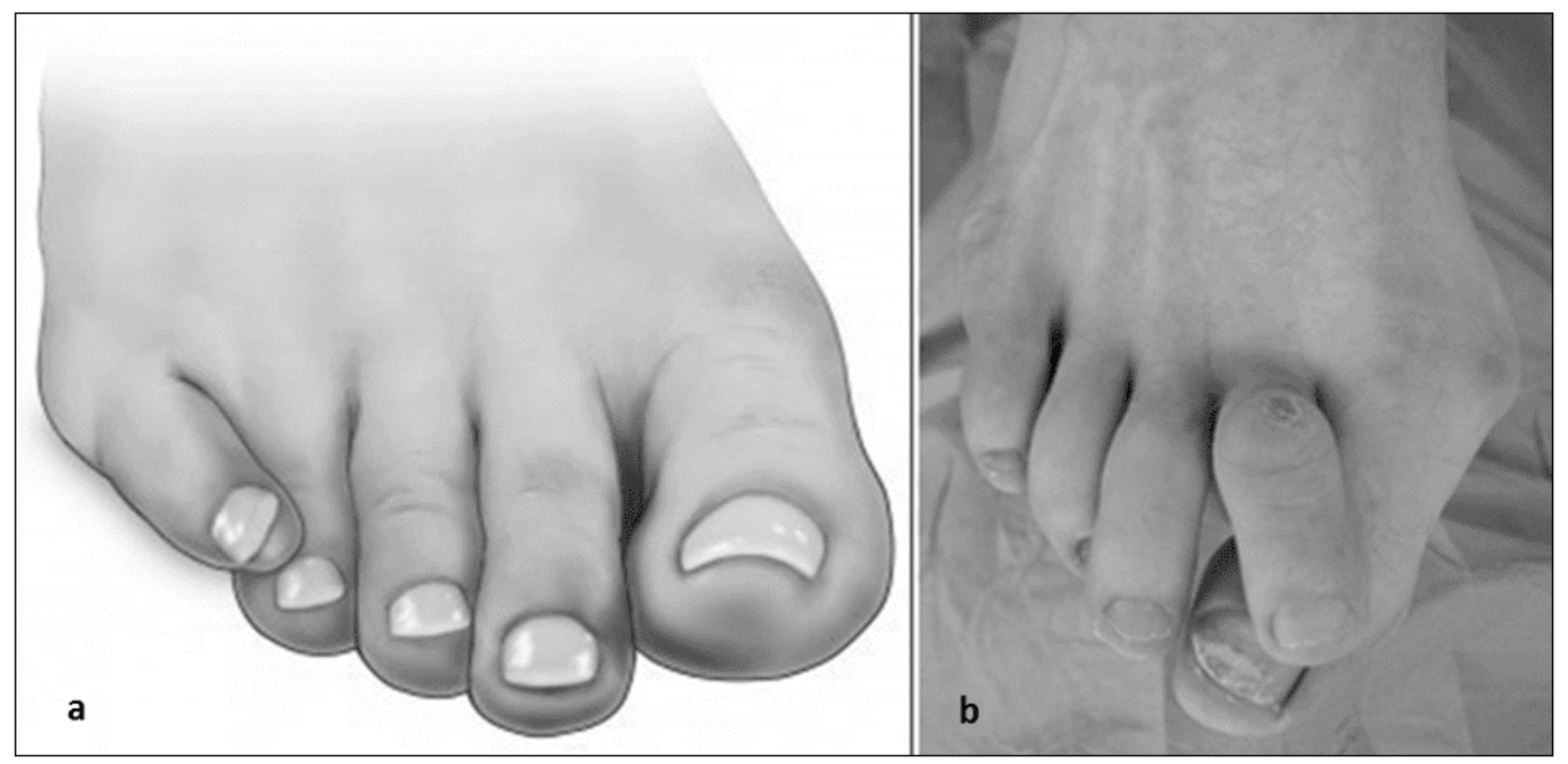

Fonte: Overlapping toes - Causes, treatment and surgery, 2016.

Embora não existam dados epidemiológicos na literatura, a sobreposição dos dígitos é frequentemente bilateral, afetando proporcionalmente meninas e meninos (TALUSAN; MILEWSKI; REACH JR, 2013). O ligamento metatarsofalangeal fica dorsiflexionado e a unha do quinto dígito, geralmente, é pequena quando comparada a unha de um dígito normal (McDANIEL; TAFURI, 1996).

Essa deformidade pode ser corrigida nos bebês com o uso de espaçadores de dígitos e é frequentemente assintomática. No entanto, se a criança começar a andar antes da correção, a sobreposição pode se tornar rígida, requerendo cirurgia para a resolução do caso (FIXSEN, 1998).

\section{CONSIDERAÇÕES FINAIS}

As malformações congênitas que acometem os pés causam grande transtorno estético, funcional e emocional. $O$ tratamento precoce é de extrema importância para o sucesso terapêutico, por isso recomenda-se que seja realizado antes da calcificação 
completa dos ossos e da criança começar a andar. O tratamento pode ser cirúrgico ou não, dependendo do tipo de malformação existente.

Conforme o grau de acometimento e do impacto que a malformação causa na vida do paciente é necessário constituir uma equipe multidisciplinar formada por médicos, enfermeiros, fisioterapeutas, terapeutas ocupacionais e psicólogos. Por isso, é fundamental para o profissional de saúde possuir o conhecimento da anatomia descritiva dos pés e das principais malformações congênitas que podem acometer essa região.

\section{REFERÊNCIAS}

ABREU, L. C.; SOUZA, A. M. B.; OLIVEIRA, A. G. Incidência de hemorragia periintraventricular em recém nascidos pré-termo e a relação com o peso ao nascer. J. Hum. Growth Dev., São Paulo, v. 17, n. 2, p. 24-30, 2007.

AMNIOTIC BAND SYNDROME. Chicago Foot Care Clinic. Disponível em: http://chicagofootcareclinic.com/footproblems/deformities/amnioticbandsyndrome.htm I. Acesso em: 29 jun. 2016.

BAEK, G. H.; LEE, H. J. Classification and Surgical Treatment of Symphalangism in Interphalangeal Joints of the Hand. Clin. Orthop. Surg., Seoul, v. 4, n. 1, p. 58-65, 2012.

BELTHUR, M. V.; LINTON, J. L.; BARNES, D. A. The spectrum of preaxial polydactyly of the foot. J. Pediatr. Orthop., Philadelphia, v. 31, n. 4, p. 435-47, 2011.

CASE, D. T.; HEILMAN, J. Pedal symphalangism in modern American and Japanese skeletons. Homo, Stuttgart, v. 55, n. 3, p. 251-62, 2005.

CHAN, M. C.; KHAN, S. A. llizarov reconstruction of chronic bilateral calcaneovalgus deformities. Chin. J. Traumatol., Chongqing, v. 22, n. 4, p. 202-206, 2019. 
CHEN, C. P. Chromosomal abnormalities associated with neural tube defects (II): partial aneuploidy. Taiwan J. Obstet. Gynecol., Hong Kong, v. 46, n. 4, p. 336-51, 2007.

CUSHING, H. Hereditary anchylosis of the proximal phalangeal joints (symphalangism). Genetics, Austin, v. 1, n. 1, p. 90, 1916.

EMBRYO.

Images

Online.

Disponível

em:

https://syllabus.med.unc.edu/courseware/embryo_images/unit-

mslimb/mslimb_htms/mslimb018a.htm. Acesso em: 01 jul. 2016.

FEMBACH, S. A. Common orthopedic problems of the newborn in Nurse. Med. Clin. North America, Philadelphia, v. 33, p. 583-94, 1998.

FIXSEN, J. A. Problem feet in children. JRSM Open, London, v. 91, n. 1, p. 18-22, 1998.

FLATT, A. E.; WOOD, V. E. Rigid digits or symphalangism. Hand, Essex, v. 7, n. 3, p. 197-214, 1975.

GORE, A. I.; SPENCER, J. P. The newborn foot. Am. Fam. Physician, Kansas City, v. 69, n. 4, p. 865-72, 2004.

HOFFINGER, S. A. Evaluation and management of pediatric foot deformities. Pediatr. Clin. North Am., Philadelphia, v. 43, n. 5, p. 1091-1111, 1996.

LIMA, P. T.; SCARFON, C. A. R. Malformações das mãos e pés. In: MUSTACCHI, Z.; PERES, S. (Orgs). Genética baseada em evidências: síndromes e heranças. São Paulo: Cid Editora, 2000. p. 801-15.

MALIK, S. Polydactyly: phenotypes, genetics and classification. Clin. Genet., Copenhagen, v. 85, n. 3, p. 203-12, 2014. 
MANDARANO-FILHO, L. G.; BEZUTI, M. T.; AKITA, R.; MAZZER, N.; BARBIERI, C. $H$. Análise casuística da sindactilia congênita: experiência com 47 pacientes. Acta Ortop. Bras., São Paulo, v. 21, n. 6, p. 333-5, 2013.

MARSH, D. J.; FLOYD, D. Toe syndactyly revisited. J. Plast. Reconstr. Aesthet. Surg., São Paulo, v. 64, n. 4, p. 535-40, 2011.

McDANIEL, L.; TAFURI, S. A. Congenital digital deformities. Clin. Podiatr. Med. Surg., Philadelphia, v. 13, n. 2, p. 327, 1996.

MCKIE, J.; RADOMISLI, T. Congenital vertical talus: A review. Clin. Podiatr. Med. Surg., Philadelphia, v. 27, n. 1, p. 145-56, 2010.

MOORE, K. L.; DALLEY, A. F. Anatomia orientada para a clínica. Tradução: Cláudia L. C. de Araújo. 5. ed. Rio de Janeiro: Guanabara Koogan, 2007.

MOORE, K. L.; PERSAUD, T. V. N.; TORCHIA, M. G. Embriologia clínica. Tradução: Adriana de Siqueira et al. 10. ed. Rio de Janeiro: Elsevier, 2016.

NOGUEIRA, F. C. S.; CRUZ, R. B.; MACHADO, L. P.; RAMOS, B. L. F.; JUNIOR, J. L. M.; PINTO, R. Z. A. Síndrome da banda amniótica: relato de caso. Rev Bras Ortop, Rio de Janeiro, v. 46, n. 4, p. 56-62, 2011.

OVERLAPPING TOES - Causes, treatment and surgery. IMG Health Publications. Disponível em: http://www.footvitals.com/toes/overlapping-toes.html. Acesso em: 29 jun. 2016.

RUSCHEL, P.; LECH, O. Sindactilia. In: PARDINI JR, A. G.; SOUZA, J. M. (ed.) Clínica Ortopédica. Defeitos congênitos nos membros superiores. Rio de Janeiro: Medsi, 2003. p. 113-119.

SKINNER, H. B.; McMAHON, P. J. Current: diagnóstico e tratamento: ortopedia-5. AMGH Editora, 2014. 
SOBOTTA, J. Extremidade inferior. In: PUTZ, R.; PABST, R. (ed.) Atlas de anatomia humana. 20. ed. Rio de Janeiro: Guanabara Koogan, 1995. p. 260-384.

SODRÉ, H. Propedêutica do pé da criança. In: LEITE, N. M.; FALOPPA, F. (org.) Propedêutica ortopédica e traumatológica. Porto Alegre: Artmed, 2013. p. 375- 6.

STEDMAN, T. L. Dicionário médico. Tradução: Cláudia L. C. de Araújo et al. 25. ed. Rio de Janeiro: Guanabara Koogan, 1996.

TALUSAN, P. G.; MILEWSKI, M.D.; REACH JR, J.S. Fifth toe deformities: overlapping and underlapping toes. Foot Ankle Spec, Thousand Oaks, v. 6, n. 2, p. 145-9, 2013.

WALL, E. J. Practical primary pediatric orthopedics. Nurs. Clin. North America, Philadelphia, v. 35, n. 1, p. 95-113, 2000.

ZAKERI, Z.; PENALOZA, C.; ORLANSKI, S.; YE, Y.; ENTEZARI-ZAHER, T.; JAVDAN, M. Cell death in mammalian development. Curr. Pharm. Des., Schiphol, v. 14, n. 2, p. 184-96, 2008.

Enviado: Setembro, 2020.

Aprovado: Outubro, 2020. 